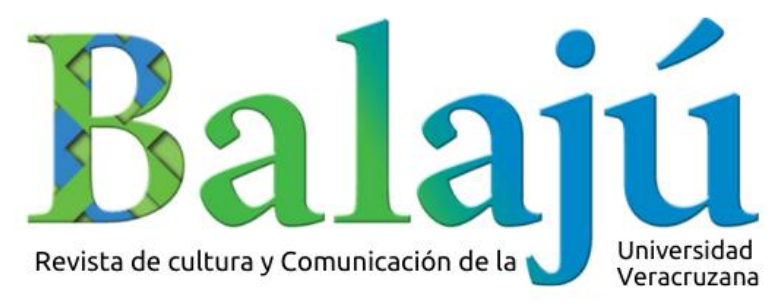

\title{
Punk en la microrregión del tequila, \\ Jalisco, 2008-2019
}

\section{Eduardo Plazola Meza}

Universidad de Guadalajara

Recibido: 19-08-2020 | Aceptado: 05-08-2021 


\section{Punk en la microrregión del tequila, Jalisco, 2008-2019}

Punk in the Tequila Microregion, Jalisco, 2008-2019

Eduardo Plazola Meza ${ }^{1}$

\section{Resumen}

El punk es una posibilidad para subvertir el orden social y simbólico del sistema cultural moderno. Conocer esta alternativa es relevante cuando los problemas sociales del desarrollo cultural inciden en la población. En este artículo, se registran datos de la escena musical alternativa del punk en los municipios del paisaje agavero Tequila, Amatitán y El Arenal, con el objetivo de reconocer la contracultura juvenil en el contexto semiurbano y rural, caracterizado por la dominación. Se hicieron entrevistas, observación de carteles y revisión del texto de canciones, con un procedimiento metodológico que consiste en extraer, ordenar, interpretar, describir y relacionar la información. En la última década hay una escena punk en aumento: se han realizado conciertos y producido objetos culturales que retoman las imágenes y los temas que distinguen a la cultura punk, abriéndose así un espacio juvenil para disentir e identificarse, que es subterráneo en el contexto local.

Palabras clave: Punk, contracultura, lenguaje simbólico, acción cultural, tequila

\begin{abstract}
Punk is a possibility of subverting the social and symbolic order of the modern cultural system. Comprehending this alternative is relevant when social problems related to development affect the population. This article provides data on the punk alternative music scene in the agave-growing municipalities of Tequila, Amatitán and El Arenal, with the aim of recognizing youth counterculture in rural and semi-urban contexts characterized by domination. It includes interviews as well as analysis of flyers and song lyrics, by means of a methodology that consists of gathering, ordering, interpreting, describing and contextualizing information. During the past decade, a growing punk scene has appeared, putting on concerts and producing cultural objects that take up images and themes from punk culture, opening a space for youth to dissent and create a subterranean collective identification at the local level.
\end{abstract}

Keywords: Punk, counterculture, symbolic language, cultural action, tequila

\footnotetext{
${ }^{1}$ Universidad de Guadalajara, Centro Universitario de los Valles. Correo: eduardo.plazola@valles.udg.mx.
} 


\section{Balajú}

\section{PUNK EN LA MICRORREgIÓN DEL TEQUILA, JALISCO, 2008-2019}

Eduardo Plazola Meza

\section{Introducción}

"Cultura punk" significa autogestión, ruido y comunidad. En su dimensión musical, es una escena alternativa en la que se producen, difunden y consumen sonidos, ideas y acciones culturales en espacios subterráneos, que están en oposición y se movilizan de forma paralela respecto a los sitios, los actos, la ideología y la música que están asociados con las "bellas artes", el capitalismo, la sociedad otrora burguesa y el fascismo.

Por lo menos durante la última década, estas propuestas tienen presencia en la microrregión del tequila, en el estado de Jalisco, México. Este territorio es relevante para la identidad del nacionalismo mexicano y el comercio legal del alcohol, pero la desigualdad social y la discriminación son problemas que están presentes. Ante esta situación, grupos de música punk de los municipios El Arenal y Tequila producen y difunden imágenes y palabras sobre resistencia sociocultural, para sostener la escena alternativa, un espacio construido en el que resulta significativo ser punk en un contexto "ranchero", o "rural" en proceso de modernización.

En general, se conoce muy poco de las culturas alternativas en estos y otros "ranchos" o ciudades pequeñas de Jalisco y del país. Aumentar los datos sobre estos asuntos puede servir para la reflexión profunda de los problemas sociales y culturales a nivel local, y para el análisis de políticas contraculturales o identidades disidentes de las nuevas generaciones, que navegan en el marco general de la globalización y la mundialización. Aquí se presenta información sobre la escena alternativa del punk en la microrregión del tequila, en el periodo 2008-2019, a partir de la revisión del contenido de letras de canciones grabadas y también de imágenes representativas expuestas en carteles de conciertos, además de las opiniones vertidas en un foro y en la entrevista realizada con los músicos de los grupos locales Contradictores, No Fun y Matacán.

\footnotetext{
${ }^{2}$ Las denominaciones 'ranchero(a)' y 'rancho' no se utilizan de forma despectiva, sino que se retoman debido a que los habitantes de estos territorios las utilizan de forma cotidiana para identificarse, por lo menos en el estado de Jalisco.
} 


\section{Balajú}

En la primera parte del artículo se discurre sobre el sentido del punk. En la siguiente se describe el contexto social y cultural de la microrregión del tequila. La tercera presenta la revisión de la escena alternativa punk local, y, en la última parte, se muestran las conclusiones.

\section{Punk no muere}

En el lenguaje de sentido común de algunas escenas alternativas, se dice que la palabra punk es el acrónimo (PUNK) de la expresión People United Not Kingdom (Pueblo Unido, No Monarquía). En el Diccionario de la Lengua Española (2020) se define como "movimiento musical [...] con carácter de protesta juvenil y cuyos seguidores adoptan atuendos y comportamientos no convencionales". Según el Oxford English Dictionary (2020), en el Reino Unido significa un tipo de rock agresivo y atuendo con picos, colores y alfileres, en tanto que en Estados Unidos de Norteamérica el término también se puede utilizar de manera despectiva para calificar a las personas como "criminales" o "inútiles".

Dale (2012) escribe que la expresión punk fue usada por primera vez en la década de los sesenta del siglo XX, para nombrar la música rock "simple" de las agrupaciones musicales de garage. El mismo investigador agrega que, en la segunda mitad de la siguiente década, la música se hizo famosa en los medios de comunicación masiva y en la industria cultural a nivel internacional, debido a lo expuesto en el movimiento británico. El autor es consciente de la dialéctica del punk entre lo tradicional y lo moderno, y lo define desde la perspectiva crítica como sustancia y modus operandi entre y en contra de la cultura dominante, que se mueve en el espacio underground o subterráne ${ }^{3}$ basado en las proposiciones: comunidad, autonomía, ruido, novedad y poder; así como en la tesis que indica: "cualquiera puede hacerlo".

Hebdige (2013) coincide con Dale (2012) al decir que el punk se volvió masivo en 1977, al ser noticia en la prensa musical comercial de Inglaterra. Afirma Hebdige (2013) que el movimiento es una subcultura que surgió en Londres en 1976, como mezcla y antítesis de las culturas juveniles de la posguerra, que estaban ligadas con los géneros musicales del rock, reggae, soul, rhythm and blues y mod. Este pensador comenta que el punk está basado en la anarquía y el Black power, el nihilismo y el solipsismo, la marginación y la alienación, el primitivismo y la parodia. Siguiendo a Althusser (1971), lo califica como "armonía chirriante", es decir, como movimiento que reproduce la ideología dominante por medio de la

\footnotetext{
${ }^{3}$ En general, esto significa que no forma parte de la economía de la industria cultural que se basa en el régimen económico capitalista.
} 


\section{Balajú}

manifestación de sus contradicciones, en este caso, las disyuntivas entre ruido/música, conciencia/creatividad, resistencia/obediencia, experiencia/significación. Las contradicciones se expresan en objetos culturales como el estilo bricolaje y repulsivo de la moda, la música y el performance, los cuales se fundamentan en la subversión, la yuxtaposición y el caos.

Sabin (2002) concuerda con Hebdige (2013) en definir el punk como subcultura, esto es, una cultura juvenil que en parte es rebelde (contracultural) y en parte es una forma de arte moderno (en el entender de las "bellas artes"). El autor observa que esta subcultura es presa de su propia ortodoxia, misma que se compone por contradicciones como ser comercial y anticomercial, sofisticado y popular, original y copia, alegre y suicida. Afirma que este tipo de cultura ha tenido enorme impacto en las formas y en el sentido del arte, así como en los movimientos culturales alternativos contemporáneos. Sabin (2002) establece que sus fundamentos son la conciencia de clase, la creencia en lo espontáneo y en el "hazlo tú mismo", además del situacionismo, el constructivismo y el relacionismo. Ubica el periodo de auge y decadencia entre los años 1976-1979, pero señala que el legado persiste en la actualidad por la trayectoria histórica de las escenas musicales del Oi!, el street punk, el anarcopunk, el hardcore, el grunge y el riot grrrl, en las que se ha puesto en juego el capital cultural que distingue al movimiento punk original.

Moore (2004) arguye que el punk responde a la "condición posmoderna", caracterizada por la "cultura de la deconstrucción", posible en un contexto sociocultural en el que las industrias culturales dominantes hacen la guerra simbólica a los consumidores (incluidos los punks), y estos responden subvirtiendo el orden simbólico a través de las expresiones estéticas. Otra vía de manifestación de esta condición es la "cultura de la autenticidad", mediante la cual se generan cotidianamente espacios, instituciones, acciones culturales e ideas alternas y subterráneas en relación con la economía capitalista, la política democrática y la sociedad hiperindividualista.

Desde el periodismo contracultural y retomando varios testimonios de los protagonistas de la hasta entonces escena subterránea de Norteamérica, McNeil (1999: 257, 281) considera que el punk era:

... algo poderoso, apoteósico... El objetivo era la libertad personal [...] decía a los chicos que no esperasen a que les dijeran lo que tenían que hacer, que crearan su propia vida, que volvieran a utilizar la imaginación, que no fueran perfectos; proclamaba que estaba bien ser un 


\section{Balajú}

aficionado, que la verdadera creatividad surge del caos, que había que trabajar con lo que tenías delante, y aprovechar positivamente las cosas vergonzosas, horribles y estúpidas de la vida.

El vocalista de Fallas del Sistema (legendario grupo del subgénero de música anarcopunk de la ciudad de Guadalajara, capital del estado de Jalisco) declaró algo parecido en el III Foro de Juventudes Rurales (2018):

... [el punk] es una alternativa a la resignación y una forma de ver, de tratar de analizar el mundo, y de comprenderlo desde una alternativa [...] nos dice, sabes, hay algo diferente, una forma diferente de vivir la vida, que esta manera casi caricaturesca en que quieren convertir al hombre. Analiza tu vida, si tú no estás de acuerdo en cómo la vives, en cómo te han obligado a vivirla, en tus manos tienes la solución, pues tu vida, no importa lo que te hayan dicho y lo que te hayan enseñado, tu vida a ti te pertenece y tú tienes la opción de transformarla y modificarla, y de transformar el rumbo del cómo vivirla.

Después de todo, es posible concluir hasta aquí que el punk es una forma de la estética negativa (véase Adorno, 2005), un movimiento social y una manifestación de la cultura posmoderna. Visto como cultura posmoderna, es la caricatura o la pudrición de las prácticas de la modernidad, pero, a la vez, representa los ideales de la misma (por ejemplo, la libertad). Puede considerarse como una especie de movimiento social porque la colectividad usa el poder en contra de ciertas maneras de pensar y de actuar que se imponen sobre otras en la sociedad, proponiendo y experimentando en la vida cotidiana otras formas de relacionarse, de agruparse y de significar lo social que son alternas, en el entendido de que representan una opción diferente que no termina por trastocar en profundidad las estructuras sociales hegemónicas. La estética negativa (siguiendo la dialéctica negativa de Adorno [2005]) en el punk alude a lo contrario de la estética "clásica" o "positiva", lo que quiere decir que las manifestaciones de la sensibilidad enfatizan lo feo, lo ruidoso, lo asqueroso, lo fétido y lo descarnado, presentándolos especialmente en el uso del cuerpo ( $l o o k^{4}$ y performance), la literatura y el sonido ruidoso.

El punk no se definirá en este artículo como subcultura o contracultura, tampoco como arte subterráneo o movimiento social libertario. Aunque se reconoce que tiene sentido nombrarlo así, se denominará escena alternativa punk. Escena como proceso y espacio de

\footnotetext{
${ }^{4}$ El look es la apariencia o aspecto de una persona en relación con su forma de vestir, el peinado y la decoración del cuerpo con tatuajes, perforaciones o cualquier otra modificación.
} 


\section{Balajú}

presentación de la "cultura punk" original. El proceso consiste en hacer autogestión para que el espacio en el que se presentan las prácticas y los significantes que lo distinguen se sostenga en el tiempo. La escena es espacio porque hay momentos y lugares específicos y múltiples para que las manifestaciones del punk sean significativas. Es un espacio producto del proceso que es alternativo, porque se mueve dentro, fuera, entre y a la par del sistema social y cultural dominante.

Por lo menos en el caso de la microrregión del tequila en Jalisco, el punk se presenta preferentemente como escena musical alternativa, es decir, como performance de la cultura original en el que se utilizan los objetos y la ideología alrededor de la música para generar identidad y comunidad en resistencia contra el sistema dominante. La escena musical del punk regional es alternativa porque transgrede y corre a la par de las percepciones y las prácticas representativas del cristianismo, el nacionalismo y el liberalismo conservador, sin conseguir por el momento desestabilizar sus estructuras, pero generando un momentum subterráneo en el contexto local, en el que es valioso ser punk sin perder del todo la identidad del tequileño (habitante del municipio Tequila) y del arenalense (habitante del municipio El Arenal).

Los estudios sobre la escena punk en Jalisco son relativamente pocos y se centran en la ciudad de Guadalajara. Marcial (2006) describe la identidad, las organizaciones y las acciones de los jóvenes punks anarquistas y skinhead del nuevo milenio que se reunían semanalmente en el Tianguis Cultural. ${ }^{5}$ Sandoval (2011) menciona que en esta metrópoli la historia del punk comienza en 1983. Afirma este autor que las bases del movimiento anarcopunk local fueron la contracultura (definida por él como conjunto de experiencias y significaciones contra el neoliberalismo, la cultura burguesa y la sociedad conservadora) y el "hazlo tú mismo" (con organización y comunitarismo), además de la propia versión de las expresiones de la estética original y de la generación de medios de comunicación independientes y autogestivos. Poma y Gravante (2016) también revisan la escena anarcopunk tapatía (gentilicio utilizado para los habitantes de Guadalajara), concluyendo lo siguiente: 1) es una cultura híbrida con dos tendencias, la política y la comercial, 2) hay una política prefigurativa y la reproducción de los símbolos originales, y 3 ) es un laboratorio del cambio social en la vida cotidiana. Otro texto es el compilado por Suplex (2015) que trata sobre el hardcore-punk, desde los ochenta y hasta mediados de la década de los noventa del siglo XX. En él se comparten testimonios,

\footnotetext{
${ }^{5}$ El Tianguis Cultural es un mercado ambulante que se coloca cada sábado en la Plaza Juárez de la ciudad de Guadalajara, en donde se realizan conciertos gratuitos y se comercializan diversos objetos culturales de las identidades disidentes.
} 


\section{Balajú}

experiencias, reflexiones, críticas, historias e imágenes (flyers ${ }^{6}$ y fotografías principalmente) de algunos músicos, promotores de conciertos y público (multitud) que estuvieron envueltos en la escena local, la cual fue calificada por algunos de los autores del documento como vanguardista y revolucionaria (Zamora), y dogmática y homogénea (Martínez).

La historia del punk en la Ciudad de México se puede apreciar en diversos audiovisuales. Minter (1986) muestra a los Mierdas Punk, una "banda" de jóvenes que se dicen sin futuro, defienden el territorio y se divierten en conciertos; ellos son "desmadrosos" (revoltosos) pero también leen y se organizan, y viven la autogestión en la cotidianidad de la marginación y de la represión social de la década de los ochenta. Martín (1994) documenta la construcción de la escena anarcopunk con entrevistas, resaltando la filosofía libertaria, la práctica de la acción directa y la generación de colectivos de jóvenes. Por su parte, Gaytán et al. (1995) utilizan fragmentos de canciones, conciertos y textos, para trazar la trayectoria histórica del movimiento punk. En uno de esos textos se dice: "Los tomamos por sorpresa, primero se asustaron de nuestra ropa; luego, no creyeron que pensáramos...; nos convirtieron en moda... y lo inevitable sucedió, le dimos portazo ${ }^{7}$ a su historia" (Gaytán et al., 1995). Un documental reciente es el de Gómez (2017), quien dialoga con personajes de la vieja y de la nueva escena musical del punk en la capital del país, registrando historias y experiencias, además de las contradicciones y la multiplicidad de manifestaciones actuales.

Lejos de la Ciudad de México y de Guadalajara (o de algunas otras metrópolis del país), es prácticamente desconocida la escena alternativa del punk, especialmente la que se ubica en localidades "rurales", semiurbanas y en ciudades pequeñas, en este caso de Jalisco. No se puede hablar de una escena musical punk interestatal o siquiera de colectivos de jóvenes "rancheros" autogestivos, ubicados en las diferentes regiones "rurales" del estado; sin embargo, hay propuestas musicales y gráficas en algunas ciudades pequeñas o "ranchos" de las regiones Valles y Lagunas del estado. ${ }^{8}$ En la microrregión del tequila de la región Valles, por lo menos desde hace una década, algunos jóvenes protagonizan la escena del punk.

\footnotetext{
${ }^{6}$ Flyers son hojas de papel pequeñas que contienen información para promover un concierto.

7 'Dar portazo' significa que fue derribada.

${ }^{8}$ En la pequeña ciudad llamada San Martín Hidalgo, que es la capital del municipio con el mismo nombre, desde 2011 la escena alternativa del punk tiene presencia por las acciones del grupo Icky Faces. El iniciador del proyecto comentó en el III Foro de Juventudes Rurales (2018) que en la ciudad se vive una situación compleja y delicada de discriminación de los jóvenes "raros", debido a la ignorancia, basada en los dogmas del cristianismo y de las instituciones del Estado. El vocalista de la agrupación definió el punk así: "Aparte de lo que es la música y el concepto de tocar en una banda de punk, tener letras contestatarias, subversivas; para mí [...] es acción directa y ser congruentes [...] yo lo vivo desde la manera de estar en una causa social [...] yo lo vivo desde mi localidad" (Francisco, 3 de octubre de 2018, III Foro de Juventudes Rurales).
} 


\section{Balajú}

\section{Microrregión del tequila}

La microrregión del tequila se integra por los municipios agaveros El Arenal, Amatitán y Tequila (otros son Magdalena y Teuchitlán, cuya principal vocación económica no es la producción de agave). Todos forman parte de la región Valles del estado de Jalisco. La microrregión se ubica hacia al noroeste de Guadalajara, a una distancia de 40 kilómetros (véase la figura 1). Es un territorio simbólico a nivel nacional e internacional porque el paisaje agavero es Patrimonio Mundial por la UNESCO (Organización de las Naciones Unidas para la Educación, la Ciencia y la Cultura), y el nacionalismo difundido por las instituciones del Estado se relaciona con el consumo del tequila, y este, a su vez, con el estereotipo del charro y con la música del subgénero mariachi. La bebida cuenta con la constancia Denominación de Origen y, por otro lado, la ciudad de Tequila es considerada como Pueblo Mágico por las instituciones gubernamentales de turismo. Se le nombra en este texto "microrregión del tequila" porque es una porción del territorio de la región Valles, y debido a que históricamente la economía, la sociedad y la cultura de los municipios que la integran han estado ligados con el mezcal de agave, que es utilizado para producir la bebida conocida como tequila.

Las cifras del Instituto Nacional de Estadística y Geografía (INEGI, 2015) indican que en 2015 habitaban casi 62000 personas en este territorio, concentradas en las ciudades capitales de cada municipio (El Arenal, Amatitán y Tequila). Datos de la misma fuente señalan que una cuarta parte de la PEA (Población Económicamente Activa) se empleaba en la industria, y alrededor de $40 \%$ en comercio y servicios; asimismo, una décima parte de todos los trabajadores ganaba únicamente un salario mínimo por mes. De acuerdo con el INEGI (2015), el grado promedio de escolaridad en ese periodo era de ocho años y, por otro lado, alrededor de $17 \%$ del total de habitantes no estaba afiliado a los servicios de salud. La mayoría de los hogares era nuclear (75\%), estando integrados por padre, madre e hijos; y, del total de viviendas habitadas (18712), 24\% disponía de internet y $80 \%$ de teléfono celular (INEGI, 2015).

Según el Sistema de Información Cultural México (SIC México, 2019), los recursos culturales en el municipio de Tequila son el Centro Cultural Juan Beckmann Gallardo, la Casa de la Cultura y el Foro Mundo Cuervo. En Amatitán, los recursos del mismo tipo son el Auditorio Municipal y la sala de lectura Elva Rivera Lizardi, mientras que en El Arenal son la Casa de la Cultura y los espacios de lectura Sala Versé y La Cima. Por su parte, la Secretaría de Cultura Jalisco (2019) enumera el patrimonio material e inmaterial en las tres 


\section{Balajú}

demarcaciones. En cuanto al primer tipo de patrimonio, sobresalen los museos alusivos al tequila, como el Museo Interpretativo del Paisaje Agavero, en El Arenal; el Museo de las Tabernas, en Amatitán, y el Museo Nacional del Tequila, en el municipio con el mismo nombre. En esta última demarcación también hay varias esculturas, murales y alto relieve que son protegidos y conservados por su valor material. En Amatitán, el patrimonio inmaterial es la fiesta de carnaval, la danza azteca y la representación de la pastorela; en El Arenal es la fiesta dedicada a San Pedro y, de forma extraña, en Tequila es el mariachi (localizado en mayor medida en las regiones Lagunas y Sureste de Jalisco).

Monzón (2014) hace un inventario y discute los espacios y las manifestaciones culturales en Tequila. En cuanto a los lugares, enumera el centro histórico, las haciendas, los museos de Los Abuelos y La Cofradía, las salas museográficas José Cuervo y Destilería Rubio, el Santuario a Santo Toribio Romo y la Parroquia de Santo Santiago, la Plaza de Armas y el Auditorio Bicentenario. Las manifestaciones culturales son las fiestas patrias, las celebraciones de la Semana Santa, el día de la Santa Cruz y el de San Juan, el Festival Cultural del Tequila y la Feria Nacional del Tequila. Este autor concluye que la población local expone bajos niveles de apropiación de los espacios culturales, pero altos niveles de representación y de socialización de las manifestaciones culturales que son tradicionales, asociados con la religión cristiana y el nacionalismo.

Castro (2017) lleva a cabo un ejercicio similar (inventariar el patrimonio) en El Arenal. Algunos de los atractivos culturales son la plaza principal y el templo de Nuestra Señora del Rosario, las haciendas La Calavera, La Fortuna y De la Providencia, y la antigua destilería La Parreña. De acuerdo con el investigador, el patrimonio inmaterial son los sonidos y bailes folclóricos, los recorridos por las calles con música de banda sinaloense y la representación del Viacrucis católico, además de las agrupaciones musicales del género regional mexicano, como las bandas sinaloenses La Orgullosa y La Pomera, la Orquesta Hermosillos, el grupo versátil Hey y el mariachi Ilusión Jalisciense. Por otro lado, el autor registra proyectos de gestión cultural como el Corredor Cultural Oaxicar, los Encuentros de Arte Vivo, el Novenario Cultural, la revista Mexcalli, el Taller Popular de Pintura Infantil y la Terraza Cultural.

Precisamente la revista Mexcalli. Turismo, Cultura y Actualidad (Chavira, 2010) enumera algunas historias, leyendas, fiestas y atractivos turísticos del municipio de Amatitán. Los atractivos son la parroquia de la Inmaculada Concepción y las empresas tequileras (por ejemplo, Tequila Herradura). Las fiestas están dedicadas a la independencia de México, al 


\section{Balajú}

Señor de la Ascensión y a las vírgenes del Carmen y Guadalupe. Las leyendas son El dragón y Ánima del templo de la Purísima Concepción, mientras que las historias son El árbol canela, $\mathrm{El}$ cortejo fúnebre y $\mathrm{El}$ arroyo de los barriles. Asimismo, en la revista se menciona la práctica de los Tangaixtes en este municipio y en El Arenal, quienes satirizan al hombre y a la mujer, y representan animales y seres horripilantes, con la intención de divertirse y por un instante subvertir el orden social y cultural público.

Así pues, en la microrregión del tequila hay diversos recursos culturales utilizados para sostener y socializar la cultura, combinando acciones culturales y símbolos de la religión cristiana, el nacionalismo, lo "popular" y lo "moderno". Este territorio es un hervidero cultural en el que hay condiciones y procesos nada despreciables para el desarrollo cultural; no obstante, el problema viene cuando otras formas y sentidos culturales que cuestionan o sobrepasan los símbolos y las acciones culturales dominantes son discriminados, aculturados y/o negados.

Aparte de los problemas en materia de cultura, en la microrregión hay problemas sociales ligados con la política económica. Según el Consejo Nacional de Evaluación de la Política Social (Coneval, 2015), 51\% de la población total en Tequila vivía en pobreza; en Amatitán, 48\% y en El Arenal, 35\%. Luna (1991) comenta que la historia de la microrregión tiene relación con intereses económico-políticos de la agroindustria del tequila que generaron una burguesía temprana que se expandió de forma independiente del capital nacional y extranjero. El mismo pensador señala que la industria "artesanal" comenzó a expandirse en la época de los hacendados de los siglos XVII y XVIII. El siguiente siglo, especialmente durante el Porfiriato, floreció una nueva oligarquía en la región. En el siglo XX, después de la Revolución mexicana, emergieron las destilerías clandestinas y, en la década de los cincuenta, la clase industrial y los "coyotes" o intermediarios para, en las últimas décadas de la misma centuria, entrar en la lógica económica del neoliberalismo.

Jiménez (2009) comenta que en Amatitán ocurrió la transformación del territorio y de la economía desde el siglo XIX, debido a la especialización en la producción de vino mezcal, lo cual lo colocó como lugar de origen de la bebida. Al respecto comenta lo siguiente: "La trasformación del entorno regional [...] queda demostrada por la forma en la que se incrementa la siembra de la planta y se establecen fábricas para elaborar el vino mezcal" (Jiménez, 2009: 14). Ayala (2016) concluye que en este municipio hay poca fuerza de trabajo calificada y una tendencia a la migración; el rompimiento entre la comunidad y los empresarios del tequila (debido a la transnacionalización de la industria), y la pobreza generada, entre otras cosas, por 


\section{Balajú}

la poca inversión de las ganancias en el territorio local. Suárez (2014) recoge diversas percepciones sobre el paisaje agavero en este municipio, en las que se dice que hay: 1) un uso vertical del poder del Estado sobre la población, 2) concepciones elitistas y mercantilistas del patrimonio y la historia, 3) oligopolios de empresas transnacionales, 4) disociación entre campesinos, 5) imposición del discurso estético y 6) desigualdad social.

González (2008) subraya que en Tequila había una clase capitalista con influencia en la política del Estado. Comenta que en el siglo XIX los empresarios invirtieron en la modernización de la industria, lo que provocó la transformación de la economía con base en la ciencia y en la tecnología, la privatización de tierras y el monopolio del mercado local. Muriá (2016: 111) menciona que en la era del neoliberalismo de finales del siglo XX la modernización de la industria tequilera implicó "nuevas formas para manejar las empresas de acuerdo con criterios y acciones de gente bien entrenada [...] con una "configuración cosmopolita"". Hernández (2009) asevera que en este siglo la capital del municipio se presenta como vernácula, exótica y mágica ante los turistas, pero tradicional y con problemas ordinarios para los residentes -la privatización del territorio, los empleos precarios, la exclusión social, la “turistificación” de la cultura y la contaminación.

En El Arenal la historia en relación con el tequila es más notoria en la primera mitad del siglo XX, cuando se establecen nuevas empresas tequileras, trascendiendo así la producción de barricas de madera para la industria de los otros municipios de la microrregión. A finales de ese siglo, los cambios económicos vinieron acompañados de cambios sociales y culturales entre la gente del poblado, como la desaparición del recato, la pérdida de la educación tradicional, el aumento en el consumo excesivo de alcohol en hombres los fines de semana, y el clasismo social entre pobres y ricos (Vázquez, 1998).

Los músicos de punk de Tequila y El Arenal describieron así el contexto microrregional contemporáneo:

... siempre tenemos este problema, principalmente en municipios pequeños, donde es una ideología la que principalmente domina [...] en el 2007 yo tenía mi mohicana, mi chamarra de cuero y mis estoperoles, entonces siempre fui muy señalado [...] caía en los prejuicios de la sociedad $[\ldots]$ los punk [sic] siempre vivimos muy reprimidos $[\ldots]$ nosotros cuando nos presentábamos [...] la policía llegaba a quitarnos el toquín [concierto], a apagarnos las luces [...] a algunos asistentes se los llevaban presos [...] simplemente por nuestra vestimenta (Billy, 3 de octubre de 2018, III Foro de Juventudes Rurales). 


\section{Balajú}

... por ejemplo, los vecinos [en Tequila] te empiezan a discriminar, y lo peor de todo es que son hipócritas, porque vas a la tienda y te saludan [...] y a tus espaldas [dicen]: ¡no mames, ${ }^{9}$ música satánica...! Casi todos están en la onda [en sintonía] de corridos, bandas [banda sinaloense], reggaeton... ven algo diferente y te discriminan bien gacho ${ }^{10}$ (Jesús, comunicación personal, 11 de junio de 2019).

En el pueblo [El Arenal] [...] hemos tenido tocadas [conciertos] donde nos han cancelado, nos han quitado el sonido, donde la policía siempre llega y hace que esto se acabe [...] hay un tipo de problemática, muy apática por parte de la sociedad, donde no se abre a expectativas nuevas, donde solamente piensan que esto nació de la noche a la mañana, sin pensar que hay un contexto histórico (Carlos, 3 de octubre de 2018, III Foro de Juventudes Rurales).

El contexto de la microrregión del tequila es el ideal para la emergencia y la alternancia de la escena del punk. Los problemas sociales y culturales son pretexto para la resistencia y el trazado de otras posibilidades, en tanto que los recursos culturales, paradójicamente, en algunas ocasiones son utilizados para disentir. Ante los diferentes problemas locales, la escena es una alternativa social, identitaria y estética.

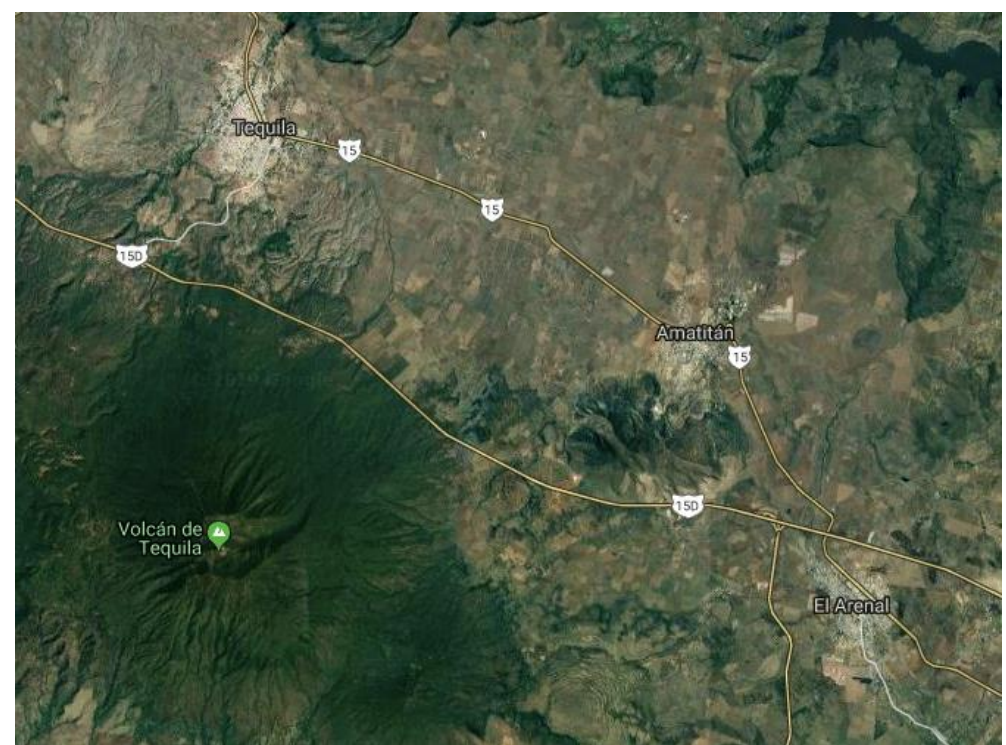

FIGURA 1. Localización geográfica de las ciudades capital de El Arenal, Amatitán y Tequila (elaboración del autor con base en https://www.google.com/maps).

\footnotetext{
9 'No mames' en este caso quiere decir: ¡no inventes!

10 'Gacho' se puede entender en este contexto como de forma violenta o exagerada.
} 


\section{Balajú}

\section{Escena alternativa punk microrregional}

\section{Movimiento}

El año 2007 puede ser considerado como el punto de partida de la escena punk contemporánea en la microrregión del tequila. La razón es simple: ese año emergen el grupo Contradictores en la ciudad de Tequila y Fottiti en la de El Arenal. En cuanto a Amatitán, no se cuenta allí con propuestas musicales de punk, aunque se hayan realizado algunos conciertos con sonidos de este tipo o hayan circulado en el lugar grupos locales de rock y heavy metal en la última década, como Alimañas, Dezechavles y Blade. Por esta razón, a partir de este punto el estudio se centrará en los otros dos municipios de la microrregión.

Los músicos de Contradictores y Matacán opinaron en el III Foro de Juventudes Rurales (2018) que la escena punk local (concentrada en El Arenal y Tequila) era parte de la escena más amplia del rock o escena alternativa, y que se enfocaba en el aspecto musical. Esto fue lo que comentaron:

Arenal siempre ha tenido música alternativa, hablamos de rock, rap $[\ldots]$ creo que la escena en Arenal sí está marcada no precisamente en el punk, porque a lo largo de la historia [...] no se conocen muchas bandas [grupo musical] [...] yo la resumiría en una escena de rock [...] aunque ha estado bajita, nunca ha desaparecido por completo, siempre hay una banda que está haciendo algo, siempre hay grupos de personas que están haciendo cosas alternativas (Carlos, 3 de octubre de 2018, III Foro de Juventudes Rurales).

... musicalmente te puedo decir que sí existe [...] a raíz de estas ideas del movimiento punk van surgiendo estos movimientos de unificación entre todos los que van a tocar [...] se comparten las bandas [grupo musical], se juntan en algunos lugares [...] se juntan algunas ideas de qué se podría hacer con la comunidad [...] todo eso surge a raíz de la música [...] si bien no existe un movimiento establecido [...] la música sí nos está dando un parteaguas (Billy, 3 de octubre de 2018, III Foro de Juventudes Rurales).

Contradictores es un grupo de Tequila del subgénero musical punk de protesta. Al inicio estaba integrado por los músicos Aarón, Erick, Rogelio y Billy, quienes comenzaron a hacer música en 2007, cuando tenían alrededor de 17 años de edad, con la intención de contradecir a y rebelarse contra la sociedad. Tiempo después, Erick dejó la agrupación y los otros integrantes siguen haciendo música hasta hoy, luego de un receso en los últimos años. La motivación para 


\section{Balajú}

decidirse por la música punk fue ir más allá del rock que sonaba ampliamente en su lugar de origen. Hasta el momento han producido un videoclip de la canción "Odio" (Ravelero, 2012) y un CD-EP ${ }^{11}$ homónimo (2012) con siete canciones, pero han compuesto otras 30 que aún no se graban. Han participado en más de 50 conciertos, la mayoría realizados en su ciudad y en otras como Guadalajara, Zapotlán El Grande, Tala y Amatitán.

Para el fundador del grupo, el punk significa:

... un estilo de vida que lo implemento [...] desde el hazlo tú mismo [...] voy partiendo de mi ideología, siempre estar cuestionándolo todo, siempre estando en contra de lo establecido [...] eso a mí me ha ayudado muchísimo [...] a expandir mis horizontes [...] En cuanto al género musical $[\ldots]$ es una manera en la que podemos expresarnos (Billy, 3 de octubre de 2018, III Foro de Juventudes Rurales).

No Fun son una agrupación novel de punk de protesta del mismo municipio. Surgieron a finales de 2017, luego de que algunos de sus músicos dejaran atrás el proyecto de covers llamado Punzada Limítrofe. El nombre del grupo es alusivo a una canción de Sex Pistols (según dijeron Jesús, Brayan y Jesús, los músicos que conforman la agrupación), el cual tomaron porque consideran que "no es divertido lo que hace el gobierno" (Jesús, comunicación personal, 11 de junio de 2019). Han grabado un CD-EP titulado No Fun (2019), que contiene cuatro canciones compuestas por ellos y un cover de Non Servium. Han participado en alrededor de 20 conciertos, muchos de ellos realizados en Tequila (algunos en compañía de Contradictores) y otros en varios municipios jaliscienses como Autlán de Navarro, El Arenal, Tala, San Martín Hidalgo y Guadalajara. El vocalista y bajista del grupo definió así el punk: "Es ser libre, expresar lo que tú quieras, romper las reglas, ser independiente [...] [y] ser unidos" (Jesús, comunicación personal, 11 de junio de 2019).

Los integrantes de No Fun y Contradictores coincidieron al indicar que en su pequeña ciudad la escena roquera es amplia y persiste la unidad entre las agrupaciones musicales, así como entre estas y la multitud del público (Billy y Jesús, comunicación personal, 11 de junio de 2019). Mencionaron que, desde hace varios años, prácticamente cada fin de semana hay algún evento musical subterráneo en Tequila y que la escena es longeva (desde la década de

${ }^{11}$ El CD-EP es un formato de disco con música, en el que se hace la presentación de algunas canciones de determinado grupo musical, sin llegar a ser un disco de larga duración y tampoco un single (sencillo) que contenga una canción con algunas versiones de la misma. 


\section{Balajú}

los ochenta del siglo XX). Ellos identificaron algunos de sus representantes históricos: Mozto, Blasted, Desorden Sin Ley, Gangrenozos, Fluydo, Último Aliento, Eko, Cuerdas Viejas, Tequila 80, Winehouse, Chorizo a Brasas, Los Villanos, Retrovisor, Evidentes, Manzana Verde, Pakistanes, Blackned, Tekistraits, Évora, Enter Sadness y Cuarta Resistencia.

En Tequila, con denominación de Pueblo Mágico, los lugares de los conciertos de punk han sido principalmente bares como Azaleas, Coyotes, Adobes, Limas, Sauzal, Amadeus, Sport Party, Los Inmortales, Tequilas y Atlanta Sport Bar, además de salones de fiesta como Huerta de Aidé, Salón Atlanta Gym, Azaleas Salón y La Herencia, y los restaurantes Wings Army Tequila, La Estación y La Eskalera. Únicamente se ha realizado uno en el zócalo de la ciudad. Muchos siguen llevándose a cabo en casas particulares y en locales rentados, promovidos especialmente por los propios músicos o amigos cercanos.

Según comentaron Billy (comunicación personal, 9 de junio de 2019) y Jesús (comunicación personal, 8 de junio de 2019), la asistencia promedio a los conciertos realizados en Tequila es de 50 personas, de los cuales menos de la mitad son punks en cuanto a sus acciones culturales en el evento (imagen corporal, danza). Algunas de las acciones del público son bailar slam, ${ }^{12}$ consumir cerveza, divertirse con los amigos, disfrutar tranquilo de la música y corear las canciones. Ambos músicos concluyeron que el concierto es el momento para unificar la escena alternativa municipal, al estar presentes en el mismo espacio de los punks los metaleros (aquellos que disfrutan de la música heavy metal), los roqueros y los raperos (a los que les gusta escuchar música rap).

En El Arenal, la escena roquera ha estado viva por lo menos desde 2005, con agrupaciones de diferentes estilos musicales tales como Bajo Cero, Black Storm, Híbrido, Black Semen, Efecto Tequila, Aerosol, Metáfora, Cenizas del Fénix y Black Panthers. En este municipio hay dos grupos del subgénero musical punk-rock que sobresalen en años recientes: Arleen y Matacán. Años atrás hubo otros que expresaban este tipo de música llamados Gallo, Aerosol y el ya mencionado Fottiti, los cuales formaron parte de la primera generación que abanderó la escena musical local en el periodo 2008-2013.

Matacán significa "zona de vigilancia" y surge en 2013, con la intención de divertirse y retratar la vida cotidiana. El grupo está integrado actualmente por Ernesto, Humberto y Carlos

\footnotetext{
${ }^{12}$ El slam es una forma de baile del público que consiste en empujones, brincos y golpes (sin el afán de dañar con dolo), moviéndose de un lado a otro o corriendo en círculos en un espacio delimitado, casi siempre frente al escenario del concierto.
} 


\section{Balajú}

(antes había otro integrante llamado Sergio), quienes provenían de y siguen participando en otros proyectos musicales. Han producido más de 15 canciones propias, siete de ellas grabadas en el CD-EP titulado Esta es mi vida (2019). Su propuesta ha formado parte de más de 40 conciertos, varios de ellos realizados en El Arenal y otros en Tequila y en Amatitán, así como en los municipios de Jalisco Atemajac de Brizuela, San Martín Hidalgo, Tala y Guadalajara. El baterista de la agrupación comentó que el punk es "una misma ideología, pero tiene diferentes significados [...] depende de nuestra experiencia en él. Para mí el punk lo puedo representar haciendo música libre, teniendo la libertad de hacer lo que quiero con mis amigos" (Carlos, 3 de octubre de 2018, III Foro de Juventudes Rurales).

En los últimos tres años, en esta municipalidad los conciertos de punk se han efectuado principalmente en casas particulares, en los salones El Patio y La Perla y en el Casino Real California. Antes se realizaron en haciendas como La Calavera y La Parreña, en los bares El Siglo, Hookas, Verse Café Bar, Boca de Mar, La Malcriada, Ksiquez y Alternativo, y en espacios públicos y universitarios como la plaza principal, la unidad deportiva, el parque skate (práctica de la patineta y los patines) y el módulo municipal de la Escuela Preparatoria Regional de Amatitán. La asistencia promedio a los conciertos ha sido de más de 20 personas. Entre el total de asistentes, solamente tres a cinco gustaban preferentemente del punk. Las acciones culturales de todos los asistentes fueron consumir alcohol, bailar slam y cantar las canciones de los grupos conocidos (Carlos, comunicación personal, 3 de junio de 2019).

Hasta aquí es posible afirmar que en la microrregión del tequila hay una escena alternativa del punk en el periodo 2007-2019, sostenida especialmente por algunas agrupaciones musicales de los subgéneros conocidos como de protesta y punk-rock. La principal manifestación cultural es la música en concierto y la grabada. Los conciertos se concentran en las cabeceras municipales, especialmente en la ciudad de Tequila, abarcando en todos los municipios de la microrregión gran parte de los espacios legales e ilegales de diversión alternativa a lo largo del tiempo. Cabe resaltar que las acciones de la escena local se han enlazado con la escena alternativa de Guadalajara y con el sur de Jalisco.

La escena alternativa del punk local no está exenta de problemas, como la dificultad de no tener apoyos externos de sujetos ajenos al movimiento, el relativo poco contacto y unidad con la multitud de asistentes a los conciertos y la dependencia de la industria cultural. No obstante, tiene prospectiva en la microrregión del tequila, según indicó uno de los músicos: 


\section{Balajú}

... el punk va a pisar fuerte [...] cada vez hay más chavos [jóvenes] [...] de 11-12 años que les interesa $[\ldots]$ ya lo ven como alternativa musical $[\ldots]$ a partir de eso ellos pueden ser $[\ldots]$ la futura escena [...] Quisiera que sí hubiera un movimiento y se unieran Tequila, Amatitán, San Martín Hidalgo, Tala y Ameca; yo pienso que se harían unas redes de apoyo (Carlos, 3 de octubre de 2018, III Foro de Juventudes Rurales).

\section{Imágenes de carteles}

Antes de los conciertos, la difusión en la microrregión se realiza con carteles que circulan en el ciberespacio. Todos se elaboran en formato digital, y la gran mayoría son diseñados y difundidos por los integrantes de las mismas agrupaciones. Desde 2008 comienza la publicación en el portal de Facebook de Contradictores. Matacán empezó a difundir en el ciberespacio desde 2016, en tanto que No Fun inició en 2018. A partir de entonces no han dejado de publicarse carteles de libre acceso, y ha habido dos periodos de mayor circulación (de 2008 a 2011 y de 2016 a la actualidad).

Con la intención de estudiarlos, se descargaron 54 carteles (véase las figuras 2, 3 y 4 ) de los portales de internet, lo que indica que por lo menos se realizó la misma cantidad de conciertos en los tres municipios desde que comenzaron a publicarse. De ellos, 42 corresponden a conciertos realizados en Tequila, 10 en El Arenal y 2 en Amatitán. Los años con mayor cantidad de carteles publicados son 2010 y 2018. En Amatitán solo hay carteles los años 2010 y 2012. En El Arenal se empiezan a difundir en 2011; y en 2012 y 2014 no se publicaron. En Tequila no hay carteles de los años 2009, 2014 y 2017.

En algunos carteles no hay imágenes, solamente texto, por lo que quedaron fuera de esta revisión. También se excluyeron aquellos que promocionaran conciertos en los que no se incluyeran grupos de punk, y los realizados en otros municipios y regiones del estado que no interesan aquí. Tampoco se consideraron imágenes que no tienen relación con los fundamentos y las manifestaciones del punk; por ejemplo, aquellos casos en los que se muestran algunas mujeres o partes de su cuerpo en forma sensual, o la figura de la planta de agave característica del paisaje de la microrregión del tequila.

Los carteles elegidos presentan imágenes representativas del punk original. Estos se identificaron clasificando por fecha los carteles de cada grupo musical, y a partir de esto se observaron exclusivamente aquellos objetos que aludían a las categorías: $a$ ) oscuro, $b$ ) rebelde y c) ruidoso. Estas categorías fueron establecidas luego de una primera revisión de todos los 


\section{Balajú}

carteles, en la que se evidenció que sobresalían grafos asociados con los temas: música, política y anticristianismo, desde la perspectiva del punk.

Las imágenes que más se exhiben en todos los carteles son las alusivas a la oscuridad (véase la figura 4). Exponen cráneos humanos, algunos de ellos decorados o utilizados como objetos de decoración, y otros presentados en acción (acechando). También hay personajes como fantasmas, la calabaza de Halloween, zombis, cuervos y murciélagos. Otras figuras retomadas son el averno, el pentagrama y el libro de magia. En general, representan a la muerte y el ateísmo (característicos del rock y del heavy metal), y se utilizan para disentir de la religiosidad cristiana que apela a la luz divina, la vida en el cielo, los ciervos, la cruz y la palabra de Dios.

Las imágenes sobre el tema rebeldía aparecen en menor cantidad. Se refieren a la agresión (golpe en la cara) contra el expresidente de México Felipe Calderón por parte de un aparente seguidor del punk (véase la figura 2). También se muestran señales utilizadas en los movimientos sociales, al aparecer el puño humano cerrado y alzado y la estrella de cinco picos en color rojo. Otras formas de la desobediencia expuestas en los carteles son el cuerpo de un skinhead, la caricaturización de Sid Vicious, bajista de Sex Pistols, y la versión propia de la portada de uno de los discos de esta misma agrupación británica titulado God Save the Queen. En este caso, las imágenes representan la protesta social, uno de los distintivos de la cultura punk.

Las imágenes que aluden al ruido son aquellas en las que aparecen en primer plano instrumentos musicales como el bajo eléctrico, el contrabajo, la guitarra eléctrica, la batería y el canto amplificado de los vocalistas (véase la figura 3). En esta categoría también se puede ubicar a las cabezas con peinado estilo mohicano y con picos, y el baile tipo slam, porque resultan escandalosos para los "buenos modales" de la sociedad. La libertad de ser punk es lo que el ruido representa, puesto que los punks luchan con el cuerpo y con las expresiones de la sensibilidad para liberarse de la desigualdad social y de la discriminación, construyendo durante el proceso su propia identidad.

Las imágenes en los diferentes carteles evidencian la cultura punk, figurada por los músicos de la microrregión del tequila. Muerte y ateísmo, protesta social, música rock simple y agresiva y look grotesco son la iconografía actual que sustenta a la escena punk local. No Fun, Matacán y Contradictores son punks que reconocen y difunden a su estilo los grafos que distinguen a este tipo de cultura, genéricamente vinculados con la resistencia sociocultural que 


\section{Balajú}

busca la libertad a través de la autogestión. Las imágenes representativas simbolizan una alternativa frente a la religión, la política y la estética dominantes, especialmente para quienes se identifican con su significado y con la forma en que se usan para disentir. Sin embargo, por el momento son desconocidos los efectos sociales y culturales del consumo del contenido visual de los carteles. A pesar de esto, es probable que cada vez que son vistos se active por unos instantes la escena del punk local, sin necesidad de estar presente en los conciertos o radicar en los diferentes municipios agaveros.

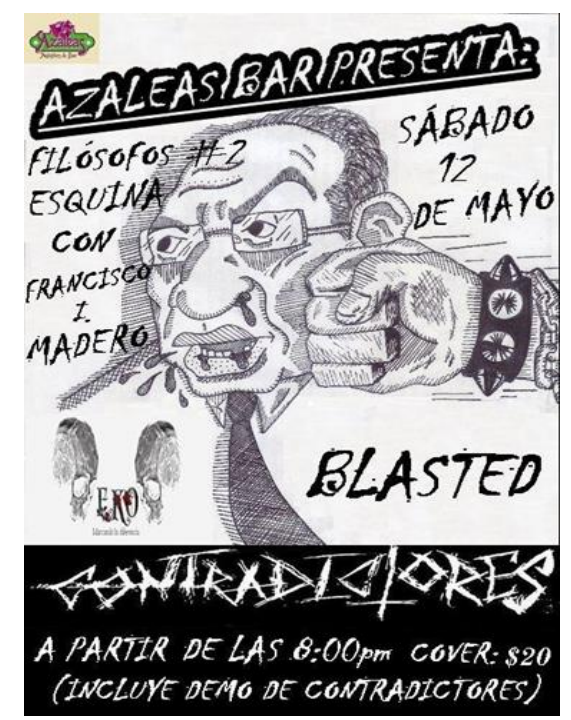

FIGURA 2. Cartel de concierto de punk en Tequila (https://www.facebook.com/Contradictores/).

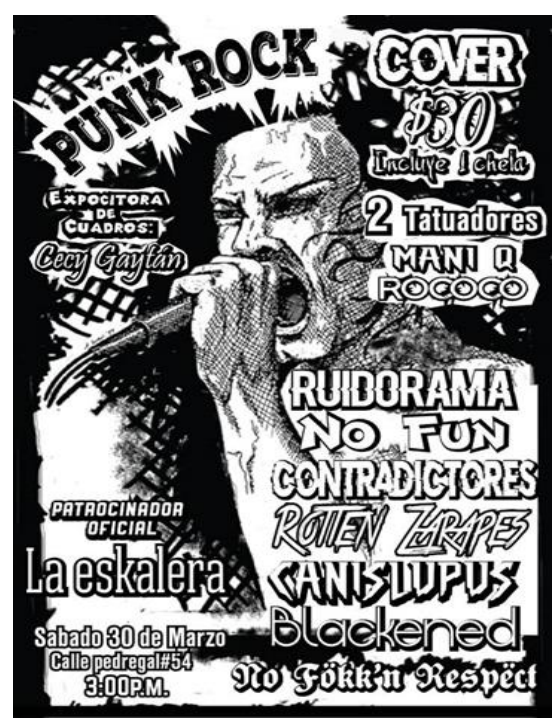

FIGURA 3. Cartel de concierto de punk en Tequila (https://www.facebook.com/nofunoficial/).

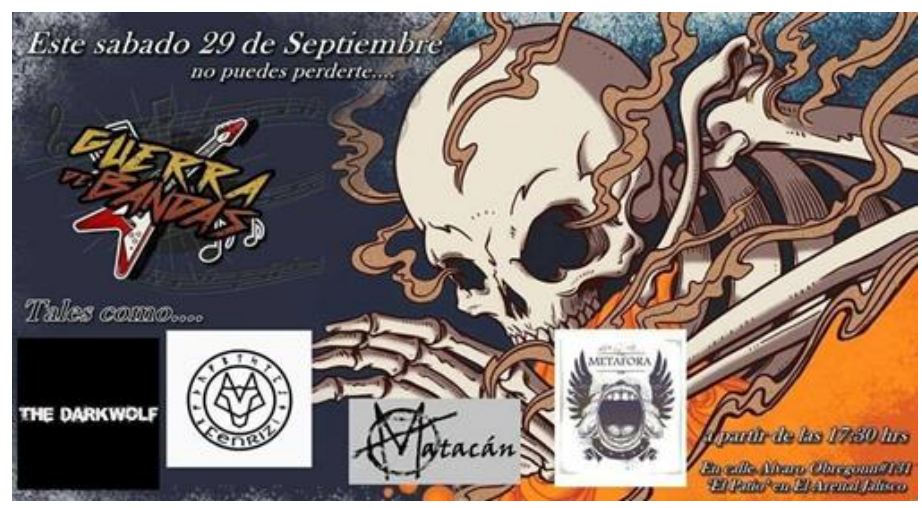

FIGURA 4. Cartel de concierto de punk en El Arenal (https://www.facebook.com/matacangdl/). 


\section{Balajú}

\section{Letra de las canciones}

Las producciones musicales de las tres agrupaciones son "caseras", es decir, grabadas en estudios de pequeña escala que son propiedad de músicos que ellos conocen o en la propia sala de ensayo con equipo electrónico prestado, sin que esto demerite la calidad del sonido. En todos los discos hay canciones con letras contestatarias y que tratan temas generales como el amor, la existencia y la vida cotidiana. Las canciones de los discos son autoría de los músicos y fueron producidas siguiendo el proceso general que consiste en llegar con ideas y propuestas de ritmos y de letras al ensayo, para con base en ello construir la canción entre todos los integrantes. La difusión de las grabaciones se ha hecho principalmente mediante plataformas de internet (MySpace, Facebook y YouTube) y en formato impreso, entregando el disco de mano en mano en los conciertos o fuera de estos eventos, valiéndose de las amistades.

Para revisar la letra de cada CD-EP se seleccionaron dos canciones que fueran explícitas en su contenido sobre el tema protesta, que es el que todos los grupos abordan en sus composiciones al menos en una ocasión. Estas canciones se transcribieron (véase el cuadro 1) para inferir del texto los problemas sociales y/o culturales, los adjetivos con los que son calificados estos y las propuestas para subvertirlos. Luego de identificar estos tres elementos, se compararon con el discurso general de la cultura punk.

Todas las canciones que conforman el disco de No Fun tratan sobre protesta. La canción "Destrucción total" versa sobre los problemas sociales de corrupción y de dictadura, y, en cuanto a los culturales, afirman que la moral imperante en la sociedad causa dificultad. No hay adjetivos calificativos para estos problemas, pero se mencionan algunos de sus efectos (desolación) y procedimientos (ejecución, liquidación, demolición). Para subvertir los problemas y sus características se propone: escupir, gritar, exterminar, vomitar, manifestar y oponer con rigor. En la canción "No seremos sometidos" el problema social es precisamente el sometimiento del pueblo (léase la gente o población) por parte de cierto sector de la sociedad, calificando a los que lo provocan como "mierda" y "escoria". Frente al sometimiento se propone hablar, joder al enemigo, defenderse como animal y despertar.

En el disco de Matacán hay tres canciones de protesta, mientras que las otras tratan sobre el amor y la vida cotidiana. La canción "Fanáticos religiosos" habla de problemas de mentalidad, violencia y fanatismo, calificando a sus causantes de mediocres, "mierda", escoria e "hijos de puta". Para enfrentar esto, no se mencionan propuestas concretas, pero se comenta que es necesario entender y comprender la situación para poder "transformar a la sociedad". 


\section{Balajú}

En la canción llamada "Perros de la calle" se hacen explícitos problemas sociales como el sistema violento, el miedo social y la pérdida de la libertad, adjetivándolos como "mundo de mierda" y sin futuro. Como propuesta para invertir este mundo, otra vez se dice que es preciso entender la realidad, pero también luchar y escapar.

El fonograma de Contradictores contiene casi en su totalidad canciones que tratan directa o indirectamente sobre protesta, y solo una aborda el asunto de la esquizofrenia. Los problemas a los que se hace referencia en la canción "Odio" son la ignorancia social, la hipocresía de la religiosidad, el capitalismo y el fascismo, los cuales son juzgados como estupidez, farsa y porquería. La única propuesta es gritar el título de la canción (odio) y ¡basta ya!, además de sugerir que no es preciso tolerar la situación. Otra de las canciones, titulada "Miseria", discurre sobre las manifestaciones de este problema social (la miseria) como el dolor, la pobreza extrema, la violencia y la represión social, calificados como agónicos y crueles. La salida que se propone es cuestionar la realidad y exigir lo que se quiere y lo que no se puede permitir nunca más.

El contenido de la letra de las diferentes canciones de punk elegidas es explícito en la mención de los problemas sociales y culturales de la realidad local, los cuales se pueden sintetizar en la dominación, esto es, la búsqueda de la obediencia de un sujeto social sobre otro por medio del capitalismo, el fanatismo religioso y el liberalismo político. En general, este problema es adjetivado como "mundo de mierda", al mismo tiempo cruel y farsa. La principal propuesta frente a este tipo de mundo es la resistencia, manifestada por medio de gritos, a la vez que se sugiere la reflexión de la realidad para poder escapar del problema.

La dominación del sistema económico, religioso y político, y, en contrasentido, la resistencia y la disidencia cultural son temas básicos e históricos de la cultura punk. En ese orden de ideas, el discurso original de esta cultura y el de las letras de las canciones de los grupos de música punk de la microrregión del tequila coinciden. La escena musical local tiene sentido y se reproduce en las canciones grabadas, provocando conflicto contra el discurso dominante cada vez que se cantan las canciones, sin que aún se sepa quiénes han sido influenciados o comparten la misma mentalidad luego de escucharlas, o cómo se han modificado el lenguaje y la comunicación a partir del uso en el espacio público y subterráneo de los significantes que caracterizan al punk. 
CUADRO 1. Contenido de las canciones de protesta de los grupos No Fun, Matacán y Contradictores

Nombre del

grupo y del

Título y contenido de la canción

Título y contenido de la canción

disco, año

No Fun

(No Fun, 2019)

\section{"Destrucción total"}

Este odio que siento yo

este dolor la situación

del no poder la corrupción

¿No podremos hacer nada?

Oponte ya a la moral,

vive ya la realidad,

día tras día te tragan ya

¿No podremos hacer nada?

Escupe grita tu dolor

extermina vomita al dictador

manifiesta ya tu rigor

¿No podremos hacer nada?

Ira y furia al igual

desolación, ejecución, liquidación,

demolición,

destrucción total
"No seremos sometidos"

Habla escupe tu sentido

aquello que siempre has querido decir

claro que tienes el control

hay que joder al enemigo

Coro: Nosotros llevamos un dolor

del no poder con este sector

de esta mierda, de esta mierda,

ya estoy harto, de esta escoria

Sé violento como un animal, porque ellos siempre te van a querer

tragar,

no seremos sometidos ya más, despierta pueblo, te quieren tragar

Coro...
Matacán

(Esta es mi vida,

2019)
"Fanáticos religiosos"

Otro día más en la realidad,

esta pinche ${ }^{13}$ gente nunca va a cambiar,

pobre conformista, puta mentalidad,

por eso viven en la mediocridad

Coro: no comprenden porque no lo entienden,
"Perros de la calle"

Abusa el sistema y la judicial, ${ }^{14}$ $\mathrm{y}$ los otros perros te quieren asustar, sales a la calle te tienes que cuidar, hay muchos disturbios que pueden disparar,

violencia, violencia, violencia, violencia,

13 'Pinche' puede ser interpretado como sinónimo de maldita(o).

14 "La judicial" era un cuerpo policiaco altamente violento, que actuaba muchas de las veces de forma impune en contra de la población presuntamente inocente en México. 
siguen siendo la misma mierda

Este país que lejos está, de transformar a la sociedad, roban, matan y violan, y siguen besando a la misma escoria,

$$
\text { Coro... }
$$

fanáticos religiosos,

hijos de puta rencorosos, adeptos mentirosos,

hijos de puta rencorosos

$$
\text { Coro... }
$$

Son la misma mierda, son la misma mierda
Coro: No puedo entender porque, todos permanecen de pie, no puedo entender porque, todos permanecen de pie

El futuro se acabó, ya no queda nada, de lo que solía ser, ya no podrás disfrutar, de tu libertad, sino te levantas a luchar, no puedes escapar, de tu realidad, este mundo de mierda, puede ser real Coro...
Contradictores

(Contradictores,
Odio esta ciudad y odio este país, odio la sociedad y toda su ignorancia, odio la religión y toda su hipocresía, odio a los políticos y toda su corrupción, odio a los fascistas y la violencia en las calles, odio el capitalismo y todo su consumismo, odio la música de hoy en día, toda estúpida carece de sentido, odio a este mundo y al ser humano, odio a los policías odio a los militares, váyanse todos a la mierda, trabajan todo el día haciéndose pendejos, molestan, humillan y golpean a la gente,
"Miseria"

Despierto al otro día, todo es agonía, a mi alrededor, todo es dolor, Coro: La miseria me acompaña, es mi compañera, de este mundo cruel, de este mundo cruel Miseria, miseria, mi fiel compañera, miseria, miseria, pobreza donde sea, miseria, miseria, hambre en las calles, miseria miseria, hagamos conciencia No tengo ningún hogar, 
no pueden detener a los criminales y

¿cómo lo harían?, ¡si ellos mismos son!,

no pueden resolver un crimen, por estar cometiendo

Coro: Basta ya de esta porquería, ¡basta ya, basta ya!, basta ya de esta pinche farsa, ¡basta ya, basta ya!

Se dicen llamar defensores del pueblo, cuando lo único que hacen es estarte molestando, no tenemos por qué soportarlo Coro... por culpa de las guerras, la policía me persigue por mi vestimenta, ¿a dónde está ese Dios del que tanto nos mencionan?, queremos comida, no queremos balas Coro...

\section{Polipuercos}

Fuente: elaboración del autor con base en los CD-EP de las agrupaciones musicales.

\section{Conclusiones}

El punk tiene presencia en el siglo XXI en la microrregión del tequila. La escena alternativa punk local resiste los problemas sociales y culturales del contexto con las letras incendiarias de las canciones y la presentación de las imágenes subversivas en los carteles de concierto, sin olvidar las prácticas culturales como el baile y el look. Especialmente en El Arenal y en Tequila, hay varios lugares donde se han realizado decenas de conciertos desde 2008 y hasta la actualidad, reuniendo a algunos punks entre la diversidad cultural del público. La escena es única, aunque comparte actores sociales, objetos culturales, espacios y procesos principalmente con la escena del rock. La trayectoria histórica, los textos, los objetos y las acciones culturales de los músicos hacen pensar que por lo menos las propuestas musicales y lo que sucede alrededor de ellas tienen futuro en esta parte del estado de Jalisco.

La escena punk microrregional es una opción para disentir de la sociedad, sin que el proceso sociocultural alternativo sea censurado y negado o consiga destruir las estructuras de dominación del cristianismo, del capitalismo y del liberalismo que caracterizan el contexto agavero. Los músicos del punk, en conjunto con los organizadores de conciertos y con la multitud del público que no se retoman aquí, se han encargado de funcionar por momentos 


\section{Balajú}

como alternativa frente al poder gubernamental, la industria de la cultura y Dios. Han conseguido que la estética negativa adorniana y la cultura punk se manifiesten cada vez que suena una de las canciones, en todas las ocasiones en que son observadas las figuras representativas en los carteles promocionales de conciertos que circulan en internet, y en el performance en concierto que ejecutan los punks. Aunque literalmente no hay un movimiento social, por lo menos entre los músicos hay autogestión y redes sociales de trabajo en construcción, basadas en el anarquismo explícito o implícito. Paradójicamente, los procesos sociales y culturales de la escena han generado un espacio latente para la libertad de los jóvenes, multiplicando así los procesos de modernización desde sus propias contradicciones.

Después de todo, continúa siendo relativamente poco lo que se conoce acerca de la escena punk local. Hace falta comprender la historia de vida de los músicos, participar en la dinámica social y en los ritos de los conciertos, analizar a la multitud del público, valorar los efectos reales en la vida cotidiana de las personas y en las estructuras sociales y culturales del contexto agavero, relacionar esta escena con el espacio y el movimiento roquero, y descubrir las hibridaciones entre la identidad "alternativa" o "disidente" y la identidad "ranchera" o "rural" en Jalisco y en otras partes de México.

\section{Referencias}

ADORNO, T. (2005). Dialéctica negativa. La jerga de la autenticidad. Akal.

AYALA, S. (2016). Destilando saberes: los gajes del oficio tequilero. Universidad de Guadalajara.

BILLY (2019). Conciertos de punk en Tequila. Entrevista, 9 de junio. ${ }^{15}$

BILLY (2018). Escena del punk en Tequila. Entrevista, 11 de junio.

CARLOS (2019). Conciertos de punk en El Arenal. Entrevista, 3 de junio.

CARLOS (2018). Escena del punk en El Arenal. Entrevista, 11 de junio.

CASTRO, I. (2017). Conocimiento y salvaguarda del patrimonio cultural en El Arenal, Jalisco, México, a través de la gestión participativa. Tesis de maestría, Universidad de Guadalajara.

CONSEJO NACIONAL DE EVALUACIÓN DE LA POLÍTICA SOCIAL (2015). Pobreza a nivel municipio, 2015.

https://www.coneval.org.mx/Medicion/Paginas/consulta_pobreza_municipal.aspx

\footnotetext{
15 Todas las entrevistas fueron realizadas por el autor.
} 


\section{Balajú}

CONTRADICTORES (2012). Contradictores. CD-EP. Tequila: autor.

CONTRADICTORES (19 de noviembre de 2019). Contradictores. Información. Facebook. https://www.facebook.com/Contradictores/.

CHAVIRA, D. (2010). Mexcalli. Turismo, Cultura y Actualidad. 4 y 7.

DALE, P. (2012). Anyone Can Do It: Empowerment, Tradition and the Punk Underground. Ashgate Publishing Limited.

GAYTÁN, P., G. Ochoa e Iti (dirs.). (1995). La década podrida 1985-1995. Cinta cinematográfica. México: Interneta, Video Popular y Cultural A. C., Subterráneo Ilimitado A. C.

GÓMEZ, E. (dir.) (2017). México capital punk. La historia no definitiva del punk mexicano. Cinta cinematográfica. México: autor.

GONZÁLEZ, M. (2008). "Modernidad y tradición de la industria tequilera (1850-1900)". Boletín Archivo General de la Nación 6 (19), 146-169.

HEBDIGE, D. (2013). Subcultura. El significado del estilo. Paidós.

HERNÁNDEZ, J. J. (2009). “Tequila: Centro Mágico, pueblo tradicional. ¿Patrimonialización o privatización?” Andamios 6 (12), 41-67.

INSTITUTO NACIONAL DE ESTADÍSTICA Y GEOGRAFÍA. (2015). Encuesta intercensal 2015 .

http://www.inegi.org.mx/est/contenidos/proyectos/accesomicrodatos/encuestas/hogare s/especiales/ei2015/

JESÚS (2019). Conciertos de punk en Tequila. Entrevista, 8 de junio.

JESÚS y BRYAN (2018). Escena del punk en Tequila. Entrevista, 11 de junio.

JIMÉNEZ, M. C. (2009). Amatitán, un caso atípico. El cultivo y aprovechamiento del maguey mezcal y la fabricación del vino mezcal. Tequila, sus efectos en la transformación del entorno regional. Benemérita Sociedad de Geografía y Estadística del Estado de Jalisco.

LUNA, R. (1991). La historia del tequila, de sus regiones y sus hombres. Conaculta.

MARCIAL, R. (2006). Andamos como andamos porque somos como somos: culturas juveniles en Guadalajara. El Colegio de Jalisco.

MARTÍN, J. (dir.) (1994). La escena punk en México. Una alternativa libertaria. Cinta cinematográfica. México: Sin Medios Producciones.

MATACÁN (2019). Esta es mi vida. CD-EP. El Arenal: autor. 


\section{Balajú}

MATACÁN (19 de noviembre de 2019). Matacán. Información. Facebook. https://www.facebook.com/matacangdl

McNEIL, L. (1999). Por favor, mátame: la historia oral del punk. Celeste.

MINTER, S. (dir.) (1986). Nadie es inocente. Cinta cinematográfica. México.

MONZÓN, M. C. (2014). Estrategia para el reconocimiento de los espacios culturales en Tequila, Jalisco, México. Tesis de maestría, Pontificia Universidad Javeriana.

MOORE, R. (2004). "Postmodernism and Punk Subculture: Cultures of Authenticity and Deconstruction". The Communication Review 7, 305-327.

MURIÁ, J. M. (2016). El famoso tequila. Porrúa.

NO FUN (2018). No Fun. CD-EP. Tequila: autor.

NO FUN (19 de noviembre de 2019). No Fun. Información. Facebook. https://www.facebook.com/nofunoficial/.

OXFORD UNIVERSITY PRESS. Punk. En Lexico.com. Recuperado el 13 de enero de 2020 de https://www.lexico.com/en. .

POMA, A. y T. GRAVANTE (2016). "Fallas del sistema: análisis desde abajo del movimiento anarcopunk en México". Revista Mexicana de Sociología 78 (3), 437-467.

PUNKS de Tequila, El Arenal, Guadalajara y San Martín Hidalgo (2018). Valles es punk. III Foro de Juventudes Rurales. Foro llevado a cabo en el Centro Universitario de los Valles, Ameca, México, Universidad de Guadalajara.

REAL ACADEMIA ESPAÑOLA. Punk. En Diccionario de la Lengua Española. Recuperado el 13 de enero de 2020 de http://www.rae.es/.

SABIN, R. (ed.) (2002). Punk Rock: So What? Routledge.

SANDOVAL, H. M. (2011). "El movimiento anarcopunk de Guadalajara. Una apuesta por resistir-existir contra y más allá del Estado/capital”. Desacatos 37, 183-190.

SECRETARÍA DE CULTURA (2019). Sistema de Información Cultural. https://sic.cultura.gob.mx/.

SECRETARÍA DE CULTURA JALISCO (2019). Patrimonio cultural material e inmaterial. https://sc.jalisco.gob.mx/patrimonio-cultural.

SUÁREZ, A. (2014). Percepciones y discursos culturales en torno al paisaje agavero. Universidad de Guadalajara.

SUPLEX (2015). Nada volverá a ser igual. Registro de la escena hardcore-punk jalisciense hasta mediados de los noventa. Abolipop Records. 
VÁZQUEZ, G. V. (1998). Estudio previo a la elaboración de un plan de desarrollo turístico del municipio de El Arenal, Jalisco. Tesis de pregrado, Universidad de Guadalajara. 